\title{
Analisa Pengaruh Interferensi Terhadap Passive Repeater Link Microwave Berdasarkan Standar ITU-T-G821
}

\section{The Analysis of Interference Effect on Passive Repeater Link Microwave based on ITU-T- G821 Standard}

\author{
Winda Ekaliya Rinanda ${ }^{1, *}$, Ade Wahyudin ${ }^{2}$, Alfin Hikmaturokhman ${ }^{3}$ \\ ${ }^{1,2,3}$ Program Studi S1 Teknik Telekomunikasi, Institut Teknologi Telkom Purwokerto \\ Jalan D.I Panjaitan No.128 Purwokerto, Jawa Tengah Indonesia 53147 \\ 1,*Penulis korespondensi: 17101232@ittelkom-pwt.ac.id \\ 2adewahyudin@ittelkom-pwt.ac.id, ${ }^{3}$ alfin@ittelkom-pwt.ac.id
}

Received on 11-11-2018, accepted on 13-11-2018, published on 28-01-2019

\begin{abstract}
Abstrak
Di suatu daerah yang memiliki dataran tinggi seperti daerah Selawangi dan Pabuaran mempunyai banyaknya pegunungan dan bukit yang membuat terjadinya kegagalan informasi yang dikirimkan pada antar BTS, kegagalan tersebut diakibatkan terdapatnya gunung yang menjulang tinggi di antara site Selawangi ke site Pabuaran, gunung tersebut dinamakan penghalang (Obstacle) yang mengakibatkan sinyal informasi yang dikirimkan dari site Selawangi ke site Pabuaran mengalami tidak Line of Sight (LOS). Untuk itu diperlukan penambahan antena pengulang yaitu (Repeater) untuk mengulang suatu sinyal radio dengan mengubah suatu pancaran radio tanpa sebuah aplikasi peralatan elektronik. Pada penelitian ini Repeater yang digunakan adalah back to back antenna karena jenis antena ini lebih baik untuk mengirimkan informasi yang diterima dan akan mendapatkan penguatan gain. Dari hasil pengujian rancangan dengan mengunakan software Pathloss 5.0, maka didapatkan hasil nilai dari kehandalan sistem yang tidak menggunakan passive Repeaterback to back yaitu availability dan outage time tidak muncul, dan dengan menggunakan passive Repeater hasil availability juga tidak muncul, Dapat disimpulkan hasil perancangan jaringan gelombang mikro menggunakan passive Repeater belum sukses karena hasil availability dan outage time tidak muncul dan membuat hasil availability tidak sesuai atau mendekati standar ITU-T-G821, oleh karena itu penulis akan mengkaji lebih lanjut dan menganalisa lebih lanjut, serta akan mengganti perangkat jika dibutuhkan.
\end{abstract}

Keywords: Microwave, Passive Repeater, Pathloss 5.0

Abstract

The failure in the information submitted between BTS is highly expected in a high area such as Selawangi and Pabuaran's high plateau with many hills and mountains. The failure is due to mountains standing tall among the site Selawangi to the site Pabuaran. The mountain acted as an obstacle, resulting in the signal information submitted from site to site Selawangi Pabuaran undergoing no Line Of Sight (LOS). Therefore, the addition of antenna repeaters for a repeat of a radio signal by changing a beam or radio without an application 


\begin{abstract}
of electronic equipment is required. In this research, the back-to-back repeater has been used because this type of antenna is better to transmit the information received and will get reinforcement of gain. From the results of testing by using design software Pathloss 5.0, then the obtained results the value of the reliability of systems that do not use passive repeater back to back, i.e., availability and outage time does not appear. By using passive repeater also, availability results do not appear, can be summed up the results of the design of the network using passive microwave Repeaters have not been successful because the results of the availability and outage time do not appear and make the results of the availability is not appropriate or approaching the standard of ITU-T-G821. Therefore the author will examine further and analyze further and replace the device if necessary.
\end{abstract}

Keywords: Microwave, Passive Repeater, Pathloss 5.0

\title{
I. Pendahuluan
}

Komunikasi radio atau biasa dikenal dengan sebutan (microwave) adalah sebuah transmisi yang mempunyai peran sangat penting dalam telekomunikasi pada jaringan telekomunikasi nirkabel. Penggunaan suatu jaringan komunikasi microwave ini dapat embantu masyarakat untuk mendapatkan layanan informasi dengan cepat karena gelombang elektromagnetik memiliki frekuensi tinggi antara $2 \mathrm{GHz}$ sampai $24 \mathrm{GHz}$ [1]. Jaringan microwave melewati suatu mekanisme perambatan dasar yang dinamakan Line Of Sight (LOS), yaitu pengiriman informasi dari antena pengirim ke antena penerima tanpa adanya obstacle (penghalang) yang dapat menghalangi perambatan suatu gelombang radio sehingga dapat mengakibatkan gangguan yang bisa disebut sebagai Multipath fading [2]. Adapun cara untuk mengatasi agar pengiriman informasi tidak terganggu oleh obstacle, dengan cara menambahkan stasiun pengulang yaitu (Repeater) di antara link microwave tersebut. Passive Repeater digunakan untuk mengulang suatu sinyal radio dengan mengubah suatu pancaran radio tanpa sebuah aplikasi peralatan elektronik [3], Passive Repeater yang digunakan adalah jenis Back to Back Antenna karena jenis ini bekerja lebih baik dan mendapatkan penguatan gain [4]. Walaupun menggunakan Repeater jaringan telekomunikasi microwave akan selalu dapat mengalami kondisi yang akan membuat suatu jaringan terdapat interferensi, gangguan interferensi dapat membuat sebuah data yang dikirimkan menjadi terhambat dan mengakibatkan berkurangnya kualitas suatu sinyal [5]. Terdapatnya Obstacle serta interferensi yang terjadi pada suatu daerah tersebut dapat dilakukan analisa dan dihitung nilai Availabilitynya, untuk mendapatkan hasil Availability yang objektif maka pada penelitian ini akan di analisa hasil Availability berdasarkan standar ITU-T-G821. Penggunaan metode ini pada perencanaan agar mendapatkan hasil yang lebih akurat dan mendapatkan nilai aAvailability yang optimal. untuk melakukan perhitungan pada nilai Availability dan interferensi yang terjadi, diperlukan perancangan link microwave dengan menggunakan software Pathloss 5.0 yang berfungsi sebagai alat bantu untuk perancangan komunikasi radio microwave.

\section{KaJian Pustaka}

Berdasarkan penelitian terdahulu menjadi suatu acuan untuk penulis dalam melakukan penelitia sehingga penulis dapat menguasai materi untuk mengkaji penelitian yang akan dibuat. Penulis mengangkat beberapa penelitian sebelumnya sebagai referensi untuk melengkapi kajian teori yang terkait pada penelitian yang akan dibuat. Bersadarkan penelitian dari Ali Sherin Yuchintya P dengan judul "Analisis Perancangan Link Microwave Passive Repeater Menggunakan Metode Barnet Vigant dan ITU Models" suatu jaringan microwave yang tidak Line Of Sight disebabkan adanya suatu penghalang yang akan mengakibatkan kegagalan suatu sistem sehingga suatu sinyal yang akan dikirimkan tidak dapat diterima dengan baik oleh BTS penerima. Dengan kondisi seperti itu maka diperlukan suatu Passive Repeater untuk mengulang atau melewatkan sinyal radio dengan mengubah arah pancar sinyal radio tersebut. Pada penelitian penulis menggunakan jenis Repeater Back to Back Antenna dan penulis menggunakan metode ITU Models dan Barnet Vigant. Sedangkan pada pemodelan vigants barnet memeprhatikan faktor kekeaaran bumi masingmasing segmen yang dihitung dari permukaan laut. Pemodelan ITU memperhatikan bidang segmen yang lebih dominan dari suatu daerah tertentu [3].

Berdasarkan penelitian Intan Erlita Dewanti dengan judul "analisis perbandingan Passive Repeater back to back dan plane reflector menggunakan pathloss 5.0" penelitian ini dijelaskan bahwa dari kedua Passive 
Repeater tersebut akan di bandingkan dan akan dianalisa mana yang lebih baik, dari hasil penelitian hasil rsl dari perancangan yang menggunakan Repeater back to back yaitu sebesar $-82,88$ dbm dan nilai Availability sebesar $99.86687 \%$. Saat menggunakan plane reflector nilai rsl yang dihasilkan sebesar $-77,07$ dbm dan nilai Availability sebesaar $99.94187 \%$, dari hasil perbandingan tersebut unjuk kerja penggunaan plane reflector menghasilkan nilai Availability yang lebih besar dari pada penggunaan Repeater back to back. Sehingga penggunaan plane reflector pada sistem jaringan transmisi microwave menghasilkan kualitas layanan yang lebih baik daripada penggunaan Repeater back to back, hasil kualitas layanan tersebut bergantung pada wilayah yang digunakan [2].

\section{Metode Penelitian}

\section{A. Alur Penelitian}

Dalam perancangan sistem transmisi gelombang mikro menggunakan Passive Repeater dengan pengaruh interferensi, akan menggunakan frekuensi kerja $13000 \mathrm{MHz}$. Pada perancangan akan di mulai dengan menentukan lokasi site bertujuan untuk melihat jalur yang akan digunakan dalam proses perancangan, sehingga jalur akan sesuai dengan kondisi dilapangan. Setelah itu perancangan akan di buat sebelum menggunakan Passive Repeater, dan setelah menggunakan Passive Repeater keduanya dalam pengaruh interferensi, pembuatan perancangan menggunakan simulator Pathloss 5.0 dan analisa kehandalam sistem transmisi gelombang mikro berdasarkan standar ITU-T-G821. Diagram alur penelitian dapaat dilihat pada gambar 1 .

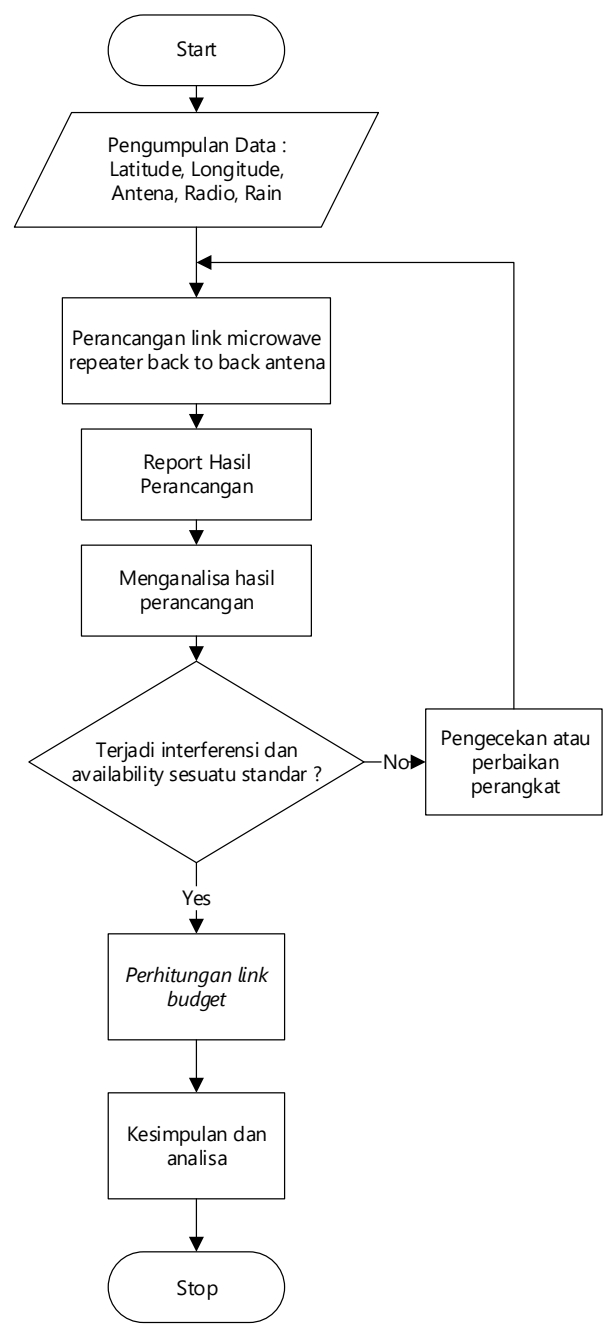

Gambar 1. Diagram Alur Penelitian 


\section{B. Penentuan Lokasi Site}

Jalur yang akan digunakan dalam perancangan jaringan komunikasi gelombang mikro dan untuk melihat kondisi geografisnya secara umum, lokasi yang akan dijadikan stasiun terdiri dari 2 site utama dengan kondisi titik koordinat terlihat pada Tabel 1 dan site pengulang (Repeater) terlihat pada Tabel 2:

Tabel I. Data Site Jaringan

\begin{tabular}{|c|c|c|}
\hline Site Name & Selawangi Bogor & Pabuaran Bogor \\
\hline Latitude & $06^{\circ} 27^{\circ} 15.65 \mathrm{~S}$ & $06^{\circ} 34^{\circ} 17.46 \mathrm{~S}$ \\
\hline Longitude & $106^{\circ} 51^{\circ} 00.77^{\circ} \mathrm{E}$ & $107^{\circ} 05^{\circ} 42.81^{\circ} \mathrm{E}$ \\
\hline Elevasi (m) & 119 & 347 \\
\hline $\begin{array}{c}\text { Path Length } \\
(\mathrm{km})\end{array}$ & \multicolumn{2}{|c|}{30} \\
\hline
\end{tabular}

Tabel II. Data Site Repeater

\begin{tabular}{|c|c|}
\hline Site Name & Repeater \\
\hline Latitude & $06^{\circ} 31^{\circ} 02.00 \mathrm{~S}$ \\
\hline Longitude & $106^{\circ} 58^{\circ} 53.01^{\circ} \mathrm{E}$ \\
\hline Elevasi (m) & 682 \\
\hline
\end{tabular}

Dengan menggunakan Path Profile berdasaarkan Map Info, dapat diketahui kondisi wilayah dari jaringan komunikasi gelombang mikro yang akan rancang, yaitu Site Selawangi Bogor dan Site Pabuaran Bogor untuk Site utama dengan jarak antar Site $30 \mathrm{~km}$. Untuk Path Profile dapat dilihat pada Gambar 2.

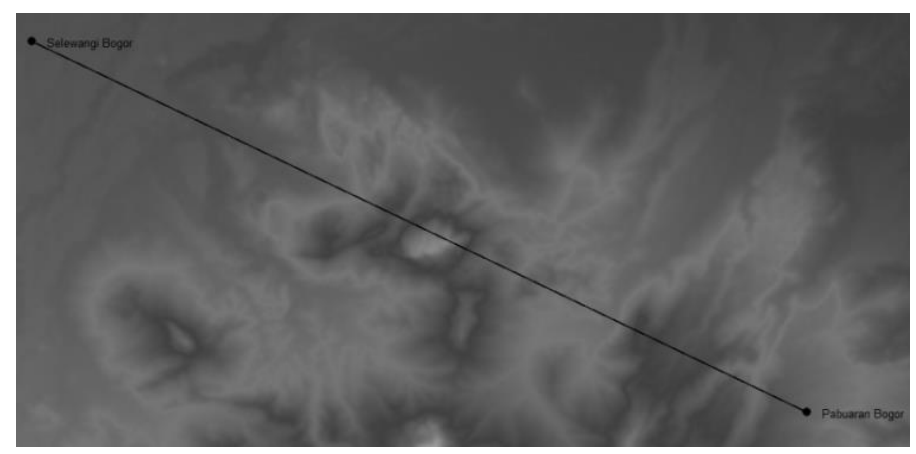

Gambar 1. Map Link Microwave

\section{Perancangan Jaringan Mikro Tanpa Passive Repeater}

Dari hasil perancangan tanpa menggunakan Passive Repeater didapatkan hasil Transmission Analysis pada Pathloss 5.0 dapat dilihat pada Gambar 3:

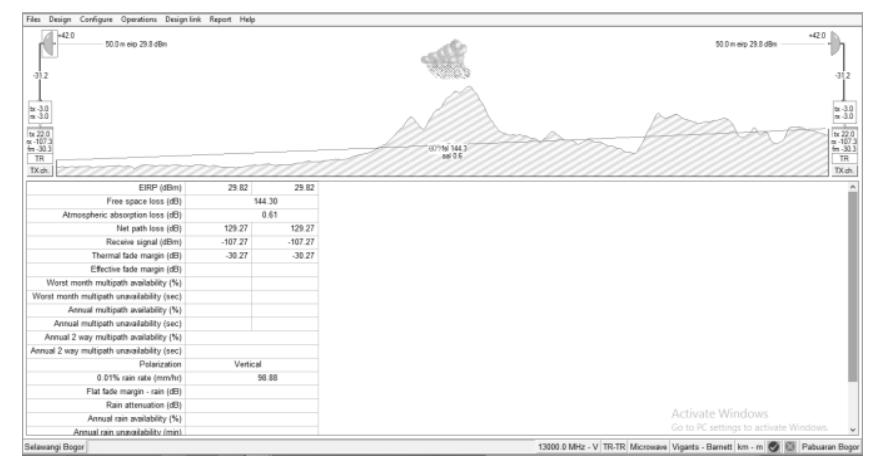

Gambar 2. Map Link Microwave 
Hasil perancangan yang dilakukan pada Pathloss 5.0 tersebut menghasilkan nilai parameter-parameter yang digunakan sebagai berikut:

\section{Gain Antena}

Gain antena digunakan untuk mengukur kemampuan antena untuk mengirimkan gelombang yang diinginkan ke arah tujuan. Besarnya gain antena dapat dicari dengan persamaan : [6]

$G=20 \log \log f+20 \log \log d+10 \log \log \eta+20.4$

Keterangan :

$\mathrm{G}:$ gain/penguatan antena $(\mathrm{dB})$

$\eta$ : effisiensi antena $(\%)$

$\mathrm{d}$ : diameter antena $(\mathrm{m})$

$\mathrm{f}$ : frekuensi kerja $(\mathrm{GHz})$

untuk menadapatkan hasil pada perhitungan nilai Gain dapat dilihat pada Tabel 3:

Tabel III. Data Inisialisasi Gain

\begin{tabular}{|c|c|c|}
\hline Parameter & Selawangi Bogor & Pabuaran Bogor \\
\hline Antena model & HP8-71W-2.4 m & HP8-71W-2.4 m \\
\hline Antena file name & $4001 \mathrm{a}$ & $4001 \mathrm{a}$ \\
\hline Antena gain $(\mathrm{dB})$ & 42.90 & 42.90 \\
\hline $\begin{array}{c}\text { Antena Height } \\
(\mathrm{m})\end{array}$ & 5.00 & 5.00 \\
\hline
\end{tabular}

2. Effective Isotropic Radiated Power (EIRP)

EIRP merupakan daya maksimal gelobang sinyal mikro yang keluar dari antena pemancar atau untuk meunjukkan nilai efektif daya yang dipancarkan antena pemancar, dalam arti lain daya tersebut sudah mengalami penguatan. Besarnya nilai EIRP dapat ditentukan dengan persamaan. [6]

$E I R P=P_{T X}+G_{T X}-L_{T X}$

Keterangan :

EIRP $=$ Effective Isotropic Radiated Power $(\mathrm{dBm})$

PTx = Daya Pancar $(\mathrm{dBm})$

GTx = Gain Penguatan Antena $(\mathrm{dBi})$

LTx = rugi - rugi pada Pemancar $(\mathrm{dB})$

Untuk menghitung nilai EIRP maka diperlukan data inisialisasi seperti yang dapat dilihat pada Tabel 4 :

Tabel IV. Data Inisialisasi EIRP

\begin{tabular}{|c|c|c|}
\hline Parameter & Selawangi Bogor & Pabuaran Bogor \\
\hline Antena gain $(\mathrm{dB})$ & 42.00 & 42.00 \\
\hline TX line model & HS2RP-50 & HS2RP-50 \\
\hline TX line unit loss (dB/100 m) & 55.60 & 55.60 \\
\hline TX line lenght $(\mathrm{m})$ & 55.00 & 55.00 \\
\hline TX line loss $(\mathrm{dB})$ & 30.58 & 30.58 \\
\hline Connector loss $(\mathrm{dB})$ & 0.6 & 0.6 \\
\hline Circulator branching loss $(\mathrm{dB})$ & 3.00 & 3.00 \\
\hline TX power $(\mathrm{dBm})$ & 22.00 & 22.00 \\
\hline
\end{tabular}

3. Isotropic Received Level (IRL)

IRL merupakan nilai level daya isotropic yang diterima oleh stasiun penerima. Nilai IRL ini adalah nilai level daya terima antena dari stasiun penerima, besar nilai IRL dapat ditentukan dengan persamaan sebagai berikut [6] :

$I R L=E I R P-F S L$ 
Keterangan :

IRL = Isotropic Received Level $(\mathrm{dBm})$

EIRP $=$ Effective Isotropic Radiated Power $(\mathrm{dBm})$

$\mathrm{FSL}=$ Free Space Loss $(\mathrm{dB})$

Untuk menghitung nilai IRL maka diperlukan data inisialisasi seperti yang terdapat pada Tabel 5 :

Tabel V. Data Inisialisasi IRL

\begin{tabular}{|c|c|c|}
\hline Parameter & Selawangi Bogor & Pabuaran Bogor \\
\hline Free Space Loss $(\mathrm{dB})$ & \multicolumn{2}{|c|}{144.30} \\
\hline Atmospheric absorption loss $(\mathrm{dB})$ & \multicolumn{2}{|c|}{0.61} \\
\hline Net path loss $(\mathrm{dB})$ & 129.27 & 129.27 \\
\hline EIRP $(\mathrm{dBm})$ & 29.82 & 29.82 \\
\hline
\end{tabular}

4. Received Signal Level (RSL)

RSL merupakan level daa yang diterima oleh piranti pengolah decoding. Nilai ini dipengaruhi oleh rugirugi jalur disisi antena penerima dan gain antena penerima. Dengan ini nilai RSL dapat dihitung menggunakan persamaan sebagai berikut : [6]

$E I R P=I R L+G_{R X}-L_{R X}$

Keterangan :

RSL $=$ Received Signal Level $(\mathrm{dBm})$

IRL = Isotropic Received Level $(\mathrm{dBm})$

GRX = Gain antenna $(\mathrm{dBi})$

LRX $=$ Receiver Loss $(\mathrm{dB})$

Hasil hitung nilai RSL dapat dilihat pada Tabel 7 :

Tabel V. Data Inisialisasi RSL

\begin{tabular}{|c|c|c|}
\hline Parameter & Selawangi Bogor & Pabuaran Bogor \\
\hline Rx threshold criteria & BER 10-6 & BER 10-6 \\
\hline $\begin{array}{c}\text { Rx threshold level } \\
(\mathrm{dBm})\end{array}$ & -77.00 & -77.00 \\
\hline Receive Signal $(\mathrm{dBm})$ & -107.27 & -107.27 \\
\hline
\end{tabular}

\section{Fading Margin (FM)}

Pada perambatan gelombang radio akan terjadi pemantulan oleh permukaan bumi, sehingga pada penerima akan menerima gelombang yang berbeda yaitu gelombang langsung dan gelombang pantul yang jarak tempuh dan waktu perambatan yang berbeda sehingga menimbulkan level daya yang diterima berbeda pada ujung penerima. Perbedaan level daya terima untuk daya pemancar yang tetap inilah disebut dengan Fading Margin (FM). Nilai FM dapat dihitung dengan persamaan sebagai berikut [7] :

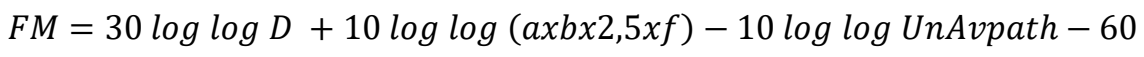

Keterangan :

FM : fading margin $(\mathrm{dB})$

$\mathrm{D}$ : panjang lintasan $(\mathrm{km})$

$\mathrm{f}$ : frekuensi kerja $(\mathrm{GHz})$

a : faktor kekasaran bumi

a : 4 ; untuk daerah halus, laut, danau, dan gurun

a : 1 ; untuk daerah kekasaran rata-rata, dataran

a : $1 / 4 ;$ untuk pegunungan dan dataran tinggi 
b : faktor iklim

b : $1 / 2 ;$ untuk daerah panas dan lembab

b : $1 / 4 ;$ untuk daerah normal

b : $1 / 8$; untuk daerah pegunungan (sangat kering)

6. Availability

Availability merupakan ukuran kehandalan sistem. Secara ideal semua sistem ini harus memiliki Availability $100 \%$. Namun hal tersebut tidak mungkin terpenuhi karena dalam suatu sistem pasti terdapat ketidakhandalan sistem (unAvailability). Terdapat dua metode untuk menghitung link budget terutama untuk Availability pada sistem yaitu metode Vigant Barnet dan meode rekomendasi ITU-R P.530-7/8. Metode Vigant Barnt merupakan persamaan perhitungan yang digunakan untk menghitung nilai Availability sistem dari persamaan fasing margin dengan memasukkan faktor jarak lintasan dan frekuensi kerja. Secara teoritis, rumus untuk menghitung Availability seperti dibawah ini [6] :

Avpath $=(1-$ UnAvpath $) \times 100 \%$

Sedangkan unAvailability dapat dinyatakan dengan persamaan dibawah ini :

$$
\text { UnAvpath }=\operatorname{axb} \times 2,5 \times f \times D^{3} \times 10^{-6} \times 10^{-F M / 10}
$$

Keterangan :

$$
\begin{array}{ll}
\text { UnAvpath } & =\text { Ketidakhandalan sistem } \\
\text { Avpath } & =\text { Kehandalan system }
\end{array}
$$

\section{ITU-T-G821}

Sedangkan Availability Objective untuk standar ITU-T-G821 berhubungan dengan performa error dari "Nx64 kb/s channels" dan memperhatikan bits error. Karena tidak ada "overhead" pada "rates" ini, sehingga hanya bit error yang dievaluasi. ITU-T G.821 biasa dipanggil dengan "out-of-services measurement". Menurut teori ITU-T G.821 yang ada sekarang tidak terlalu jelas apa yang terjadi jika terdapat "loss of signal" atau AIS pada sisi receiver. Karena ketika koneksinya unavailable maka keduanya akan mengalami "kecacatan" yang akan bertahan selama 10 detik. [20] Availability Time disebutkan secara searah, karena hamapir semua outages mempengaruhi Availability secara searah atau dua arah. Berikut adalah Availability Objective [8][10]:

Tabel VI. Availability Objective Dua Arah

\begin{tabular}{|c|c|c|c|}
\hline $\begin{array}{c}\text { Grade } \\
\text { Circuit }\end{array}$ & Class Radio Section (km) & Availability $(\boldsymbol{\%})$ & Jarak/Hop (km) \\
\hline High & 2500 & 99.997 & 46.7 \\
\hline \multirow{4}{*}{ Medium } & 1280 & 99.997 & 46.7 \\
\cline { 2 - 4 } & 2280 & 99.996 & 46.7 \\
\cline { 2 - 4 } & \multirow{2}{*}{350} & 99.98 & 50 \\
\cline { 2 - 4 } & \multirow{2}{*}{450} & 99.995 & 10 \\
\cline { 2 - 4 } & & 99.95 & 50 \\
\cline { 2 - 4 } & & 99.99 & 10 \\
\hline
\end{tabular}

Tabel VII. Availability Objective Satu Arah

\begin{tabular}{|c|c|c|c|}
\hline $\begin{array}{c}\text { Grade } \\
\text { Circuit }\end{array}$ & Class Radio Section (km) & Availability $(\boldsymbol{\%})$ & Jarak/Hop (km) \\
\hline High & 2500 & 99.9990 & 46.7 \\
\hline \multirow{4}{*}{ Medium } & 1280 & 99.9990 & 46.7 \\
\cline { 2 - 4 } & 2280 & 99.9987 & 46.7 \\
\cline { 2 - 4 } & \multirow{2}{*}{350} & 99.9980 & 50 \\
\cline { 2 - 4 } & \multirow{2}{*}{450} & 99.9996 & 10 \\
\cline { 2 - 4 } & & 99.9950 & 50 \\
\cline { 2 - 4 } & & 99.9990 & 10 \\
\hline
\end{tabular}




\section{Perancangan Jaringan Microwave Menggunakan Passive Repeater}

Passive Repeater dibutuhkan ketika jaringan transmisi microwave di tempat yang memiliki beberapa penghalang (obstacle) yang tidak dapat dihindari, seperti pegunungan atau gedung. Passive Repeater digunakan untuk mengulang sinyal radio dengan mengubah arah pancaran radio tanpa aplikasi peralatan elektronik. Antenna pasive back-to-back Repeater melibatkan menempatkan dua antena pada ketinggian tertentu pada tower ketika dua link sedang diimplementasikan. Antenna satu akan terhubung langsung ke yang lain melalui jalur pendek dari waveguide. Cara kerja Passive rpeater Back to Back Antenna dapat dilihat pada Gambar 4 [9]:

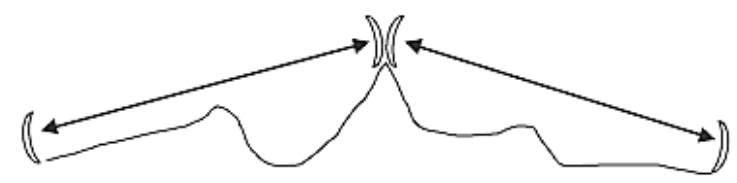

Gambar 2. Passive Repeater Back to Back Antenna

Pada perancangan menggunakan back to back antenna menggunakan frekuensi kerja yang sama dengan sebelumnya yaitu $13000 \mathrm{MHz}$. Dengan menggunakan Back to Back Antenna nilai gain yang diberikan dapat ditentukan dengan persamaan sebagai berikut : [9]

$$
G=G_{A 1}-G_{A C}+G_{A 2}
$$

Keterangan :

$\mathrm{GA} 1$ = gain salah satu antena Repeater $(\mathrm{dB})$

$\mathrm{GA} 2$ = gain dari antena lain Repeater $(\mathrm{dB})$

$\mathrm{GAC}=$ coupling loss (waveguide) antena (dB)

Untuk menghitung nilai Availability pada sistem komunikasi gelombang mikro menggunakan Passive Repeater dapat dilihat pada persamaan (6) dan (7). Setelah ditambahkan Passive Repeater hasil yang muncul pada Transmission Analysis pada Pathloss 5.0 dapat dilihat pada Gambar 4 [9] :

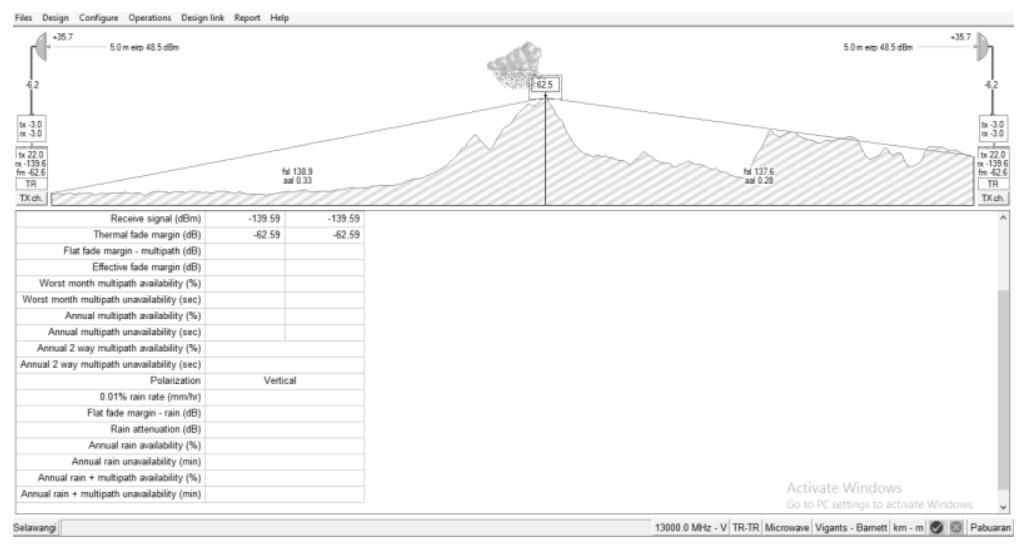

Gambar 3. Transmission Analysis Mengunakan Passivw Repeater 


\section{Hasil Dan Pembahasan}

\section{Path Profile}

Berdasarkan analisa Path Profile, dapat diketahui kondisi wilayah tempat perencanaan jaringan komunikasi gelombang mikro yang akan dirancang yaitu pada site Selawangi ke site Pabuaran. Berdasarkan hasil yang didapatkan secara umum maka dapat dianalisa sebagai berikut :

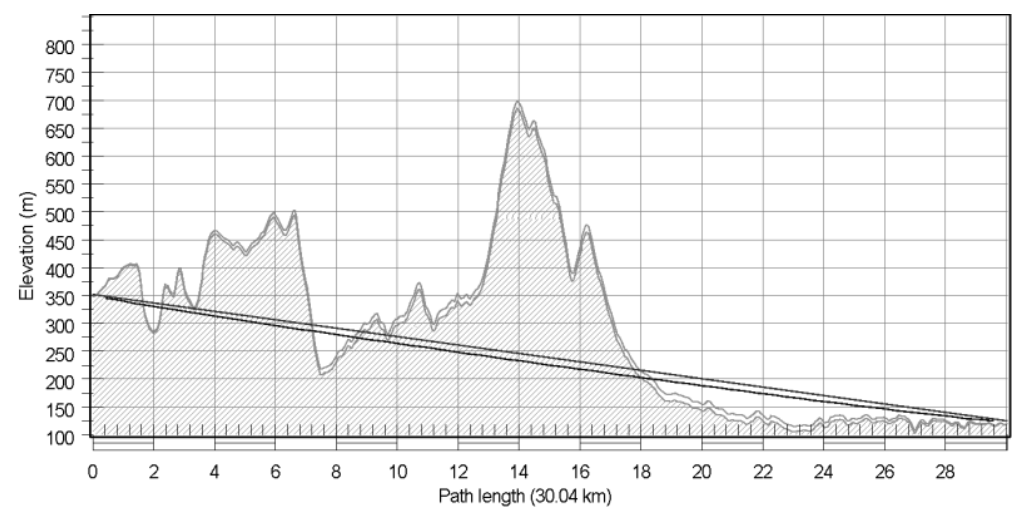

Gambar 4. Path Profile Site Selawangi ke Site Pabuaran

Berdasarkan Gambar 5 diatas dapat dilihat Path Profile Site Selawangi dan Site Pabuaran dengan jarak $30.04 \mathrm{~km}$. Dimana terrain antar site tersebut adalah pegunungan dengan tinggi antena di Site Selawangi adalah 5 meter dan 5 meter di Site Pabuaran. Dengan mempertimbangkan faktor kelengkungan bumi (K factor) adalah 1.33 .

\section{Summary Report Tanpa Repeater}

Berdasarkan hasil simulasi dengan menggunakan Pathloss 5.0 didapatkan hasil annual rain Availability sebesar $99.97501 \%$. nilai yang dihasilkan pada perancangan ini tidak memenuhi standar kualitas Availability yang ditentukan oleh ITU-T-G821, karena hasil Availability dan outage time tidak muncul, ketidak munculan tersebut dikarenakan terdapatnya suatu penghalang yang menyebabkan sinyal yang dikirimkan tidak mengalami LOS (Line Of Sight), sedangkan untuk komunikasi gelombang mikro harus memiliki nilai Availability sebesar 99.9800 - 99.9966\%. hasil Summary report tanpa Repeater dapat dilihat pada Tabel 10 dibawah ini :

Tabel VIII. Summary report tanpa Repeater

\begin{tabular}{|c|c|c|}
\hline Parameter & Selawangi Bogor & Pabuaran Bogor \\
\hline Thermal fade margin (dB) & 22.13 & 22.13 \\
\hline Effective fade margin (dB0 & - & - \\
\hline Annual 2 way multipath Availability (\%) & - & - \\
\hline Annual 2 way multipath unAvailability (sec) & - & - \\
\hline Annual rain Availability $(\%)$ & - & - \\
\hline Annual rain + multipath Availability (\%) & - & - \\
\hline
\end{tabular}

\section{Summary Report Menggunakan Repeater}

Berdasarkan hasil simulasi dengan menggunakan Pathlos 5.0 didapatkan hasil yang sama dengan sebelumnya yaitu tanpa Repeater hal ini tentu saja tidak memenuhi atau mendekati standar yang ditentukan oleh ITU-T-G821, karena hasil Availability dan outage time tidak muncul, karena bertambahnya Repeater maka jarak akan semakin jauh dan jenis perangkat sangat berpengaruh. Hasil summary report menggunakan Repeater dapat dilihat pada Tabel 11 dibawah ini : 
Tabel IX. Summary report Menggunakan Repeater

\begin{tabular}{|c|c|c|}
\hline Parameter & Selawangi Bogor & Pabuaran Bogor \\
\hline Thermal fade margin (dB) & -62.59 & -62.59 \\
\hline Effective fade margin (dB0 & - & - \\
\hline Annual 2 way multipath Availability $(\%)$ & - & - \\
\hline Annual 2 way multipath unAvailability $(\mathrm{sec})$ & - & - \\
\hline Annual rain Availability $(\%)$ & - & - \\
\hline Annual rain + multipath Availability $(\%)$ & - & - \\
\hline
\end{tabular}

\section{KESIMPULAN}

Dari hasil pengujian pada perancangan dengan menggunakan Pathloss 5.0, maka didapatkan kesimpulan antara lain :

1. Nilai kehandalan sistem dari yang tidak menggunakan Repeater dan yang telah menggunakan Repeater pada Pathloss 5.0, mendapatkan Availability yang tidak muncul.

2. Nilai outage time dari yang tidak menggunakan Repeater dan yang telah menggunakan Repeater pada Pathloss 5.0, mendapatkan nilai yang tidak muncul.

3. Pada peracangan juga terdapat pengaruh interferensi yang mengakibatkan kualitas sinyal menjadi buruk.

Dapat disimpulkan hasil perancangan jaringan gelombang mikro menggunakan Passive Repeater belum sukses karena hasil Availability dan outage time tidak muncul, oleh karena itu penulis akan mengkaji lebih lanjut dan menganalisa lebih lanjut, serta akan mengganti perangkat jika dibutuhkan agar.

\section{UCAPAN TERIMAKASIH}

Penulis mengucapkan Terima Kasih kepada segenap akademis Fakulatas Teknik Telekounikasi dan Elektro di Institut Teknologi Telkom Purwokerto atas bantuan secara moral sehingga penulis dapat menyelesaikan karya ilmiah ini dengan baik.

\section{DAFTAR PUSTAKa}

[1] Hikmaturrokhman, Alfin. "Analisa Pengaruh Interferensi Terhadap Availability pada Jaringan Transmisi Microwave Menggunakan Software Pathloss 5.0 Studi Kasus di PT. Alita Praya Mitra." Jurnal Ilmiah (Ecotipe) Jurusan Teknik ElektroFakultas Teknik Universitas Bangka Belitung 1.2 (2014).

[2] Dewanti, Intan Erlita, Ade Wahyudin, and Alfin Hikmaturokhman. "Analisis Perbandingan Passive Repeater Back-To-Back Antenna Dan Passive Repeater Plane Reflector Menggunakan Pathloss 5.0 .Senatek 2017"

[3] Hikmaturokhman, A., Wahyudin, A., Yuchintya, A. S., \& Nugraha, T. A. (2017, November). Comparison analysis of Passive Repeater links prediction using methods: Barnett Vigants \& ITU models. In New Media Studies (CONMEDIA), 2017 4th International Conference on (pp. 142-147). IEEE.

[4] Muhammad Rizal Kurniawan, "Analisa Implementasi Double Passive Repeater terhadap Nilai Availability Link Transmisi Wilayah Bogor Menggunakan Pathloss 5.0," STT Telematika Telkom Purwokerto, pp. 1-5, Agustus 2017.

[5] Hikmaturokhman, Alfin. "Diktat Kuliah Gelombang Mikro." Purwokerto: Akatel Shandy Putra Purwokerto (2007).

[6] Alfin Hikmaturokhman and Ade Wahyudin, Perancangan Jaringan Gelombang Mikro Menggunakan Pathloss 5.0, 1st ed. Yogyakarta, Indonesia: Pustaka Ilmu, 2018.Ramadhani R. D., Priyanto, A., Sidiq, M. F. 2018., Enhancement of K-Parameter Using Hybrid Stratified Sampling and Genetic Algorithm, INFOTEL, 10 (1), pp.22-27.

[7] Robert G.Winch, Telecomunication transmission system microwave, fiber optic, mobile cellular radio, data and digital multiplexing. Singapore, 1993.

[8] George Kizer, Digital Microwave Communication, 1st ed., Inc Sons, Ed. Canada, United States Of America: John Wiley, 2013.

[9] L Freeman Roger, Telecommunication Transmission Handbook. New York, 1981.

[10] ITU-T-G.821, "ITU-T G.821 Telecommunication Standardization sector of ITU," International Telecommunication Union (ITU-T), pp. 1-34, desember 2002 